\title{
Sistem Aplikasi Perpustakaan Berbasis Web Menggunakan Framework Codeigniter pada SMAS Islamic Centre
}

\section{Web Based Library Application System Using Code Igniter Framework at SMAS Islamic Center}

\author{
Bisan Dwi Heriyanto ${ }^{1}$, Ilham Aji Kurniawan ${ }^{2}$, Irfan Taufik ${ }^{3}$ \\ ${ }^{1,2,3}$ STMIK Raharja; Jl. Jend. Sudirman, Babakan, Kec.Tangerang, Kota Tangerang, Banten, \\ Banten 15117, 021-552-9692 Jurusan Teknik Informatika, STMIK Raharja, Tangerang \\ bisandwi@raharja.info ${ }^{1}, \underline{\text { ilham.aji@ raharja.info }}{ }^{2}, \underline{\text { irpantaufik50@gmail.com }}^{3}$
}

\begin{abstract}
Abstrak
Sistem aplikasi peminjaman dan pengembalian buku ini merupakan system aplikasi yang diharapkan bisa membantu staff perpustakaan dalam mengelola data perpustakaan dengan efektif dan efisien. Selain itu juga demi tercapainya tujuan system itu sendiri yaitu memudahkan pustakawan atau pustakawati dalam mencari buku dan kemudahan dalam segala hal. Dalam pembuatan aplikasi ini juga ada data pendukung yang di perlukan di antaranya data anggota, buku, transaksi, dan alur dari system yang sebelumnya. Dari data-data tersebut diharapkan bisa menjadi dasar pembuatan aplikasi ini agar dapat menyajikan informasi yang di butuhkan dengan cepat dan effisien. serta untuk meningkatkan kinerja petugas perpustakaan. Persyaratan anggota perpustakaan adalah siswa/siswi SMAS ISLAMIC CENTRE. Kemudian membuat formulir pendaftran untuk menjadi anggota siswa/siswi SMAS ISLAMIC CENTRE. Hasil yang di harapkan dari pembuatan system ini adalah agar data-data yang selama ini disimpan dan di kelola secara manual dapat mulai dikomputerisasikan sehingga dapat mengefektifkan kinerja serta mempermudah petugas perpustakaan di dalam menjalankan kegiatan yang berhubungan dengan perpustakaan itu sendiri.
\end{abstract}

Kata kunci-Perpustakaan, Administrator, Sistem, Aplikasi, Sekolah.

\begin{abstract}
This lending and return application system is an application system that is expected to help library staff in managing library data effectively and efficiently. In addition, for the sake of achieving the goal of the system itself is easier for librarians or librarians in search of books and ease in all things. In the making of this application there is also supporting data in need include data members, books, transactions, and the flow of the previous system. From these data is expected to be the basis of making this application in order to convey the information needed quickly and efficiently.serta to improve the performance of librarians. The requirements of library members are students of SMAS ISLAMIC CENTER. Then the registration form to become a student member of SMAS ISLAMIC CENTER. The expected result of making this system is that the data that has been stored and managed manually can begin to be computerized so that it can streamline the performance as well as simplify the librarian in running the activities related to the library itself.
\end{abstract}

Keywords - Library, Administrator, System, Applications, School. 


\section{PENDAHULUAN}

Perpustakaan sekolah adalah sarana dan prasarana yang diharapkan dapat menunjang proses belajar mengajar di sekolah sehingga mendorong terwujudnya kualitas pendidikan Indonesia yang berperan penting dalam mencerdaskan kehidupan bangsa. Keberadaan perpustakaan sekolah adalah untuk memenuhi kebutuhan informasi bagi masyarakat lingkungan sekolah yang bersangkutan. Perpustakaan berperan sebagai media dan sarana untuk menunjang kegiatan belajar mengajar ditingkat sekolah. Dengan meningkatnya fungsi perpustakaan secara maksimal maka diharapkan akan menambah pendidikan atau pembelajaran yang maksimal bagi para murid. Salah satu langkah yang di terapkan untuk meningkatkan fungsi dari perpustakaan itu sendiri adalah dengan membuat sebuah sistem informasi pengoahan data serta sistem yang dapat memonitoring minat baca siswa yang efektif dan efisien.

Proses pengolahan data perpustakaan yang masih manual masih dengan cara mencatat dengan buku besar, Belum adanya pencarian buku otomatis untuk ketersediaan buku di perpustakaan untuk siswa, proses penyerahan data laporan yang masih manual masih dengan penyerahan ke kepala sekolah untuk penyerahan laporannya, Belum adanya monitoring data minat baca siswa di perpustakaan SMAS Islamic Centre.

Tujuan penelitian ini adalah membuat sistem pengolahan data perpustakaan yang kompleks agar di dapatkan sistem yang dapat memudahkan user dalam pengolahan data dan pembuatan laporan, membuat sistem yang dapat memudahkan siswa dalam pencarian buku.

\section{METODE PENELITIAN}

Pada penelitian ini penulis menggunakan metode analisi SWOT yang dimana suatu cara menganalisis faktor-faktor internal dan eksternal menjadi langkah-langkah strategi dalam pengoptimalan usaha yang lebih menguntungkan. Dalam analisis faktor-faktor internal dan eksternal akan ditentukan aspek-aspek yang menjadi kekuatan (Strengths), kelemahan (Weakness), kesempatan (Opportunities), dan yang menjadi ancaman (Treathment) sebuah organisasi. Dengan begitu akan dapat ditentukan berbagai kemungkinan alternatif strategi yang dapat dijalankan dalam pengelolaan dan pengembangan suatu aktifitas memerlukan suatu perencanaan strategis, yaitu suatu pola atau struktur sasaran yang saling mendukung dan melengkapi menuju ke arah tujuan yang menyeluruh.

CodeIgniter adalah framework aplikasi web yang bersifat open source yang digunakan untuk membangun aplikasi PHP yang dinamis. Tujuan utamanya adalah untuk membantu pengembangan pengembang CodeIgniter untuk mengerjakan aplikasi lebih cepat daripada menulis semua kode dari nol. Karakteristik CodeIgniter adalah sebagai berikut: a) Memiliki karakteristik yang fleksibel dan ringan untuk memudahkan dalam belajar, memodifikasi, dan mengintegrasikan Library and Helper; b) Menggunakan pola MVC sehingga struktur kode yang dihasilkan lebih terstruktur dan memiliki standar yang jelas; dan c) Menghasilkan URL yang sangat ramah. Di CodeIgniter diminimalkan gunakan \$_GET dan diganti dengan URL.

Struktur kerja CodeIgniter dimulai dari browser yang akan berinteraksi via controller. Kemudian controller akan menerima dan membalas semua permintaan dari browser. Untuk data, controller akan meminta model dan untuk pengontrol UI / template akan meminta untuk melihat. Bila browser meminta halaman web maka router akan menemukan controller yang seharusnya menangani permintaan tersebut. Nantinya akan digunakan controller untuk mengakses data dan tampilan model untuk menampilkan data. MVC digunakan untuk memisahkan akses data dan logika bisnis dari presentasi data dan interaksi pengguna. Pemisahan dilakukan agar setiap perubahan dalam logika presentasi atau logika bisnis tidak berpengaruh satu sama lain sangat kompleks. Solusi pemisahan MVC diharapkan dapat meningkatkan fleksibilitas dan usabilitas aplikasi. Arsitektur MVC memisahkan aplikasi menjadi tiga bagian, yaitu Model, View dan Controller. Model: Representasi database, termasuk tabel desain terhadap hubungan yang ada antar tabel. Fungsi utama dari model ini adalah untuk menangani data " mengambil data dari database, memasukkan data ke dalam database, 
manipulasi data melalui validasi data. View: View untuk membuat model data yang diberikan dan akan mengirimkan gerak / aktivitas dari konsistensi tampilan data ke perubahan yang terjadi. Dengan mengelompokkan semua tampilan dan kode presentasi di satu tempat, akan memudahkan untuk mengubah tampilan tanpa mempengaruhi logika bisnis dan data. Controller: Controler mendefinisikan perilaku yang terjadi pada aplikasi, dan kemudian memetakannya ke dalam tindakan dari pengguna ke model. Pengontrol akan sangat erat kaitannya dengan View, karena setiap interaksi pengguna yang akan dilakukan akan ditunjukkan oleh View to a response oleh Controller. Di dalam controller akan ada metode yang akan merespon perilaku aplikasi.

Proses pengumpulan data yang penulis lakukan dalam penyusunan Tugas Akhir ini sebagai berikut:

a. Observasi

Observasi adalah pengamatan langsung terhadap kegiatan yang diteliti berfungsi untuk melengkapi data yang diperoleh, maka dilakukan pengamatan mengenai kegiatan yang berlangsung di perusahaan tersebut. Pada metode penelitian observasi ini peneliti melakukan pengamatan langsung ke SMAS Islamic Centre untuk mencari data alur sistem perpustakaan yang berjalan

b. Wawancara

Wawancara adalah proses memperoleh keterangan dengan cara tanya jawab dan bertatap muka antara pewancara dengan penjawab yang bertujuan untuk mengetahui sistem yang berjalan dan apa saja kekurangan dari sistem tersebut. Pada metode penelitian wawancara ini peneliti melakukan wawancara dengan bapak Asykur Binurika, S.IP selaku staff perpustakaan untuk mencari data sistem yang dibutuhkan oleh $u$ ser.

c. Studi Kepustakaan

Metode ini bertujuan untuk mencari literature yang berisi teori-teori yang berkaitan dengan masalah yang akan dibahas. Dalam hal ini pengumpulan data diperlukan pedoman sepert buku-buku referensi yang berhubungan dengan penulisan ini.

Dalam penyusunan sistem ini metode yang digunakan oleh penulis adalah metode perancangan model UML (Unified Modelling Language) dan perancangan database menggunakan MySQL serta bahasa pemrograman dengan menggunakan PHP (Hypertext Preprocessor).

\section{HASIL DAN PEMBAHASAN}

\subsection{Analisa Permasalahan}

Menurut data observasi yang sudah peneliti jalani sistematika peminjaman di SMA Islmaic Centre tersebut masih sangat manual dan demikian penjabaran masalah yang telah peneliti analisa :

a. Pencarian

Sering kali siswa pada saat pencarian buku di perpustakaan tersebut tidak dapat menemukan buku yang di inginkan di karenakan tidak tahunya ketersediaannya buku tersebut

b. Pendataan

Pendataan buku dalam hal peminjaman dan pengembalian buku siswa masih sangatlah manual staff perpustakaan juga sering ke repotan dengan laporan yang sering berceren dan data peminjaman yang hilang sehingga buku - buku yang telah di pinjam pun hilang.

c. Monitoring

Sulit nya memonitoring minat baca siswa yang masih menggunakan grafik yang belum tentu akurat datanya. 
Berdasarkan data observasi yang sudah di jalan terdapat banyak kelemahan daam sistem perpustakaan yang sedang berjalan di sekolah tersebut yang dimana semua sistemnya di lakukan dengan cara yang masih sangat manual.

\subsection{Analisa SWOT}

Analisa SWOT dilakukan dengan mengidentifikasi kekuatan dan faktor-faktor positif yang berasal dari internal organisasi (Strenght),kelemahan dan faktor-faktor negatif dari internal (Weakness), peluang atau kesempatan dan keuntungan dari faktor eksternal (Opportunities) dan ancaman atau resiko yang dipengaruhi oleh faktor eksternal organisasi (Treaths).

Tabel 1. SWOT

\begin{tabular}{|c|c|c|}
\hline OT & $\begin{array}{l}\text { STRENGHT } \\
\text { Tersedianya SDM yang baik } \\
\text { dalam menjalankan program } \\
\text { yang terkomputerisasi } \\
\text { Mempunyai fasilitas yang } \\
\text { cukup untuk menjalankan } \\
\text { program yang } \\
\text { terkomputerisasi }\end{array}$ & $\begin{array}{l}\text { WEAKNESS } \\
\text { Sulit untuk mendapatkan } \\
\text { data karena } \\
\text { penyimpanannya masih } \\
\text { manual } \\
\text { Sering kali siswa sulit dalam } \\
\text { pencarian buku di } \\
\text { perpustakaan }\end{array}$ \\
\hline $\begin{array}{l}\text { Opportunity } \\
\text { Pemanfaatan teknologi } \\
\text { informasi untuk } \\
\text { peminjaman dan } \\
\text { pegembalian buku } \\
\text { Pendataan buku } \\
\text { peminjaman dan } \\
\text { pengembalian yang } \\
\text { terkomputerisasi dengan } \\
\text { baik } \\
\text { Pencarian buku } \\
\text { perpustakaan yang dapat } \\
\text { dilakukan dengan cepat } \\
\text { dengan memanfaatkan } \\
\text { program aplikasi }\end{array}$ & \begin{tabular}{l}
\multicolumn{1}{c}{ STRATEGI SO } \\
Merancang aplikasi \\
peminjaman dan \\
pengembalian buku \\
perpustakaan yang dapat \\
memudahkan dalam \\
memanage buku-buku \\
perpustakaan dan dalam hal \\
pembuatan laporan dan \\
diharapkan juga dapat \\
memudahkan siswa dalam \\
mencari buku perpustakaan.
\end{tabular} & $\begin{array}{l}\quad \text { STRATEGI WO } \\
\text { Memanfaatkan program } \\
\text { peminjaman dan } \\
\text { pengembalian buku } \\
\text { perpustakaan untuk } \\
\text { memudahkan dalam } \\
\text { pembuatan laporan dengan } \\
\text { cepat dan akurat. } \\
\text { meminimalisir dalam } \\
\text { kehilangan buku } \\
\text { perpustakaan }\end{array}$ \\
\hline $\begin{array}{l}\text { THREAT } \\
\text { Manipulasi data yang } \\
\text { mungkin saja dilakukan oleh } \\
\text { operator } \\
\text { Penggunaan user yang } \\
\text { bukan haknya atau hacker }\end{array}$ & $\begin{array}{l}\quad \text { STRATEGI ST } \\
\text { Membuat pendataan } \\
\text { peminjaman dan } \\
\text { pengembalian buku lebih } \\
\text { sistematis dan } \\
\text { terkomputerisasi dengan } \\
\text { baik } \\
\text { pencarian buku } \\
\text { perpustakaan guna } \\
\text { memudahkan siswa dalam } \\
\text { pencarian buku dengan } \\
\text { mudah }\end{array}$ & $\begin{array}{l}\text { STRATEGI WT } \\
\text { Memberikan kemudahan } \\
\text { bagi sekolah dalam } \\
\text { memanage perpustakaan } \\
\text { dalam hal pendataan } \\
\text { peminjaman } \\
\text { pengembalian buku } \\
\text { perpustakaan }\end{array}$ \\
\hline
\end{tabular}

3.3 Rancangan program pada usecase diagram

Dalam merancang program peneliti menggunakan usecase diagram sebagai gambaran sistem yang berjalan. Untuk rancangannya bisa di liat pada gambar di bawah ini 


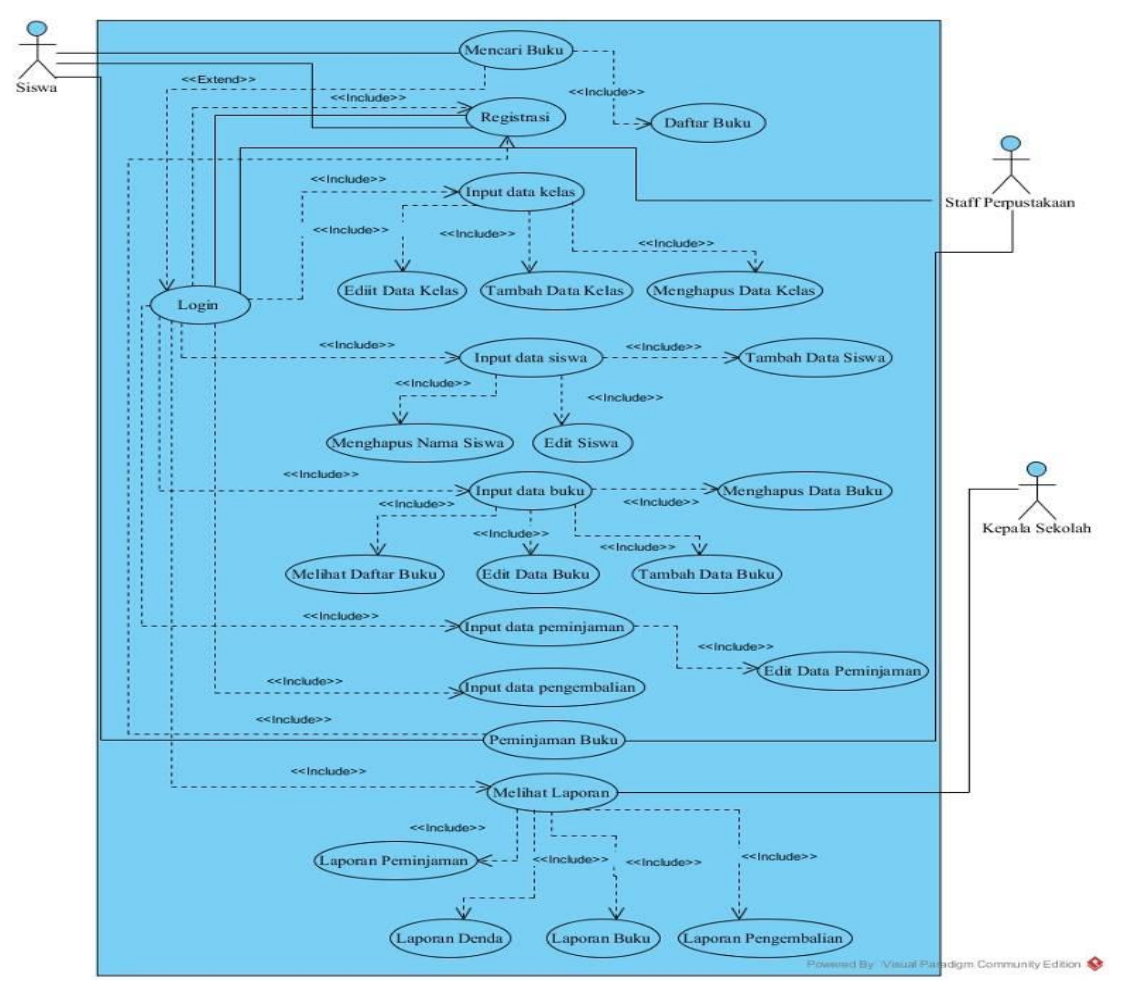

Gambar 1. Usecase diagram

Pada gambar di atas dijelaskan bahwa alur sistem program usulan yang akan di terapkan yaitu : Siswa dapat melakukan pencarian buku dengan aplikasi dengan demikian siswa dapat mengetahui ketersediaan buku apa sajakah yang tersedia di perpustakaan. Registrasi, siswa dapat melakukan registrasi untuk melakukan peminjaman buku dan pengembalian. Login, sebagaimana sebuah system, jika staff perpustakaan ingin melakukan kegiatan dalam sebuah aplikasi maka si staff perpustakaan harus melakukan sebuah login untuk memverifikasi keamanan sistem. Setelah itu admin melakukan pendataan anggota apabila ada siswa yang ingin meminjam buku dan apabila sudah terdaftar staff perpustakaan dapat langsung melakukan pendataan peminjaman buku. Setelah itu pada proses pengembalian buku siswa sebagai actor menyerahkan buku yang telah dipinjam dan staff perpustakaan melakukan cek data peminjaman apakah siswa mengembalikan buku tepat pada waktunya atau lebih, jika lebih siswa diharapkan membayar denda terlebih dahulu.setelah itu baru admin input data pengembalian buku yang telah di kembalikan oleh peminjam. Membuat laporan, pada bagian ini staff perpustakaan dapat membuat laporan dengan cepat dan tepat serta mudah dalam aplikasi dan dalam menu laporan juga tersedia laporan data buku, laporan data peminjaman, dan laporan data pengembalian. Periksa laporan, setelah laporan data yang telah di buat oleh staff perpustakaan, kepala sekolah juga bias memeriksa laporan dengan menggunakan hak akses sebagai admin pada aplikasi atau memeriksa hasil cetak laporan yang telah di buat oleh staff perpustakaan.

\subsection{Relasi Database}




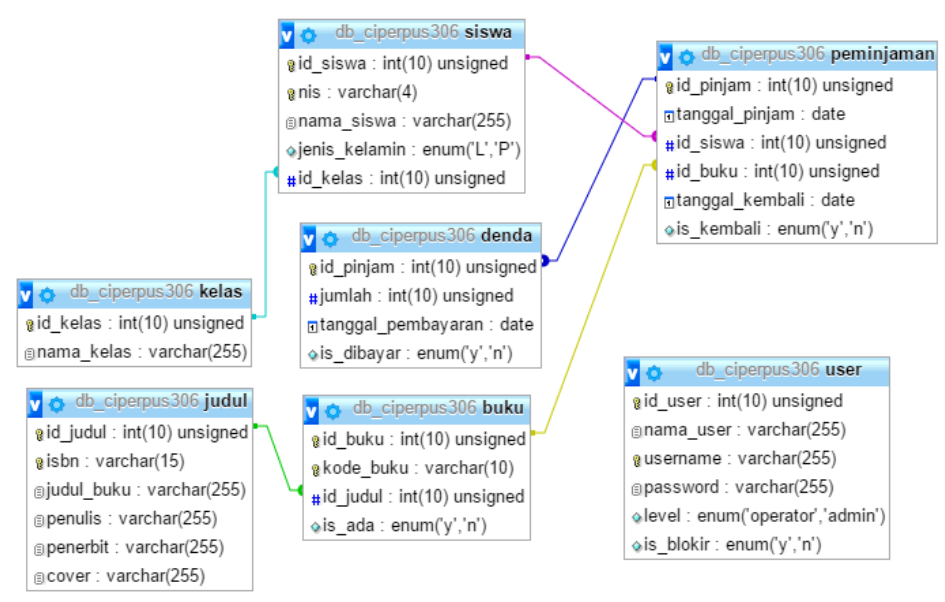

Gambar 2. Relasi Database

3.5 Implementasi Program

3.5.1 Tampilan Menu Buku

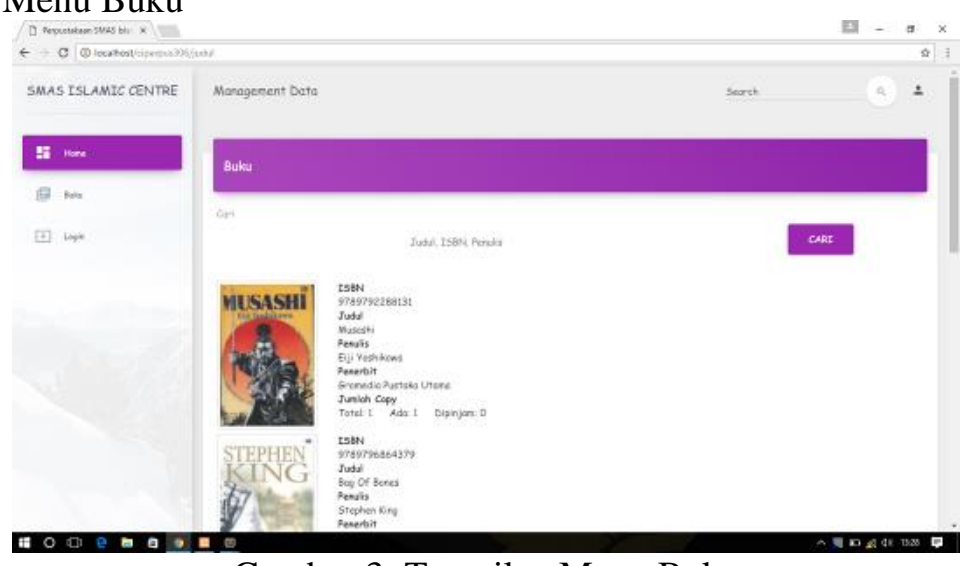

Gambar 3. Tampilan Menu Buku

Pada gambar 3.5.2 di atas adalah halaman yang berfungsi sebagai tampilan awal program dimana menu buku di tampilan awal ini digunakan untuk melihat daftar judul buku yang terdapat di dalam program.

\subsubsection{Tampilan Menu Login}

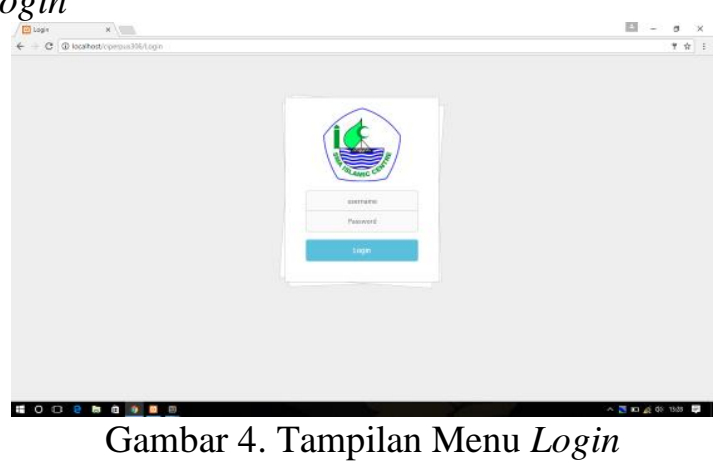

Pada gambar 3.5.3 di atas adalah halaman yang berfungsi untuk menu login yang dimana digunakan user untuk memasuki halaman utama atau dashboard aplikasi.

\subsubsection{Tampilan Menu Kelas}




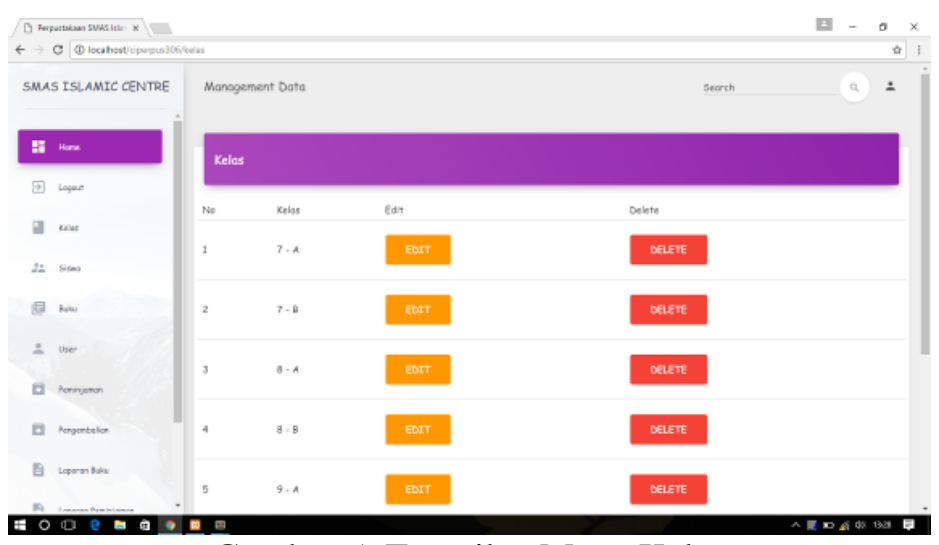

Gambar 5. Tampilan Menu Kelas

Pada gambar 3.5.4 di atas adalah halaman yang berfungsi untuk melihat daftar kelas yang ada, kita bisa mengedit nama kelas dan menghapus nama kelas tersebut.

\subsubsection{Tampilan Menu Masukan Buku}

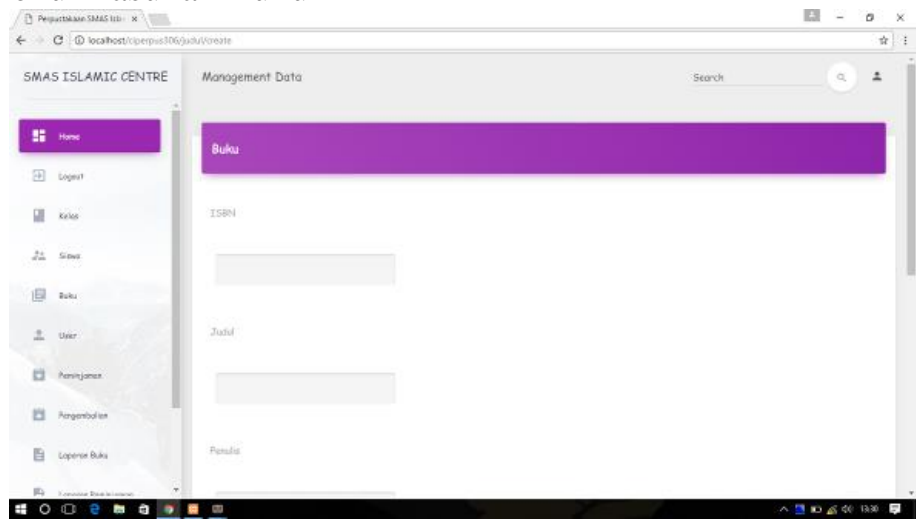

Gambar 6. Tampilan Menu Masukan Buku

Pada gambar 3.5.5 di atas adalah halaman menu buku yang berada di dalam tampilan setelah user melakukan login. Dalam menu buku di atas user dapat menambahkan daftar buku yang ingin di masukan kedalam program.

\subsubsection{Tampilan Menu Buat Peminjaman}

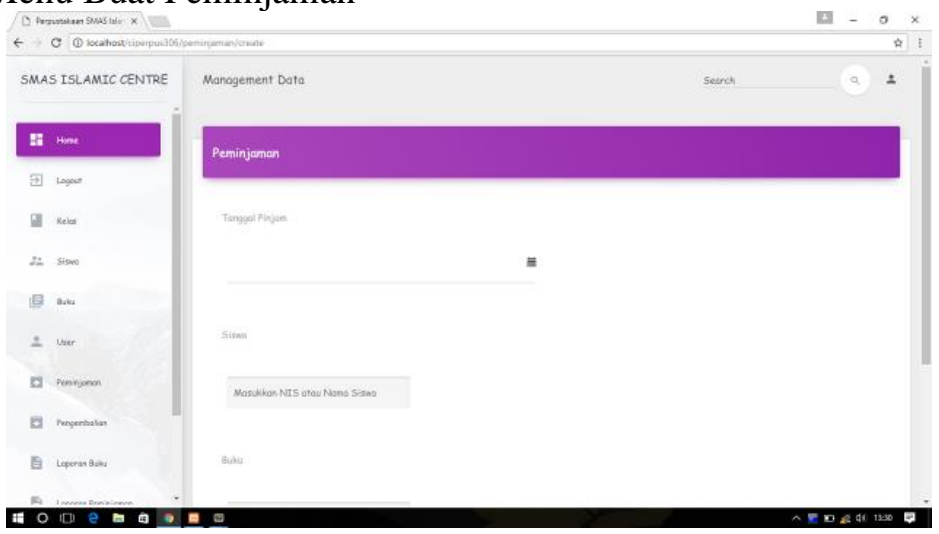

Gambar 7. Tampilan Menu Buat Peminjaman

Pada gambar 3.4.7 di atas ini user dapat menambah daftar peminjam yang akan meminjam buku. 
Sistem Aplikasi Perpustakaan Berbasis Web...

3.5.6 Tampilan Menu Pengembalian

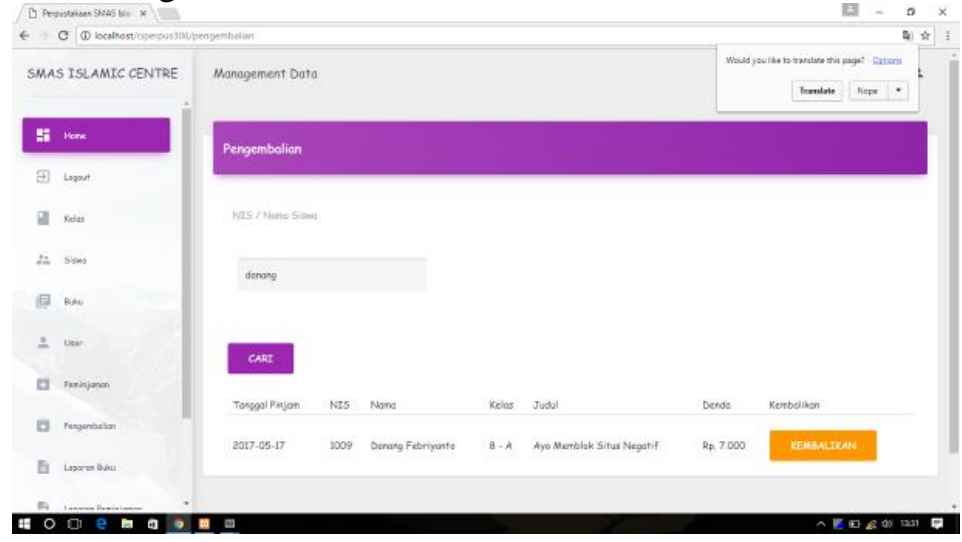

Gambar 8. Tampilan Menu Pengembalian

Pada gambar 3.5.8 di atas user dapat mencari dan mengubah status peminjam yang ingin mengembalikan buku beserta denda apabila yang bersangkutan telat mengembalikan buku sesuai tanggal yang sudah di tentukan.

\subsubsection{Tampilan Menu Laporan Peminjaman}

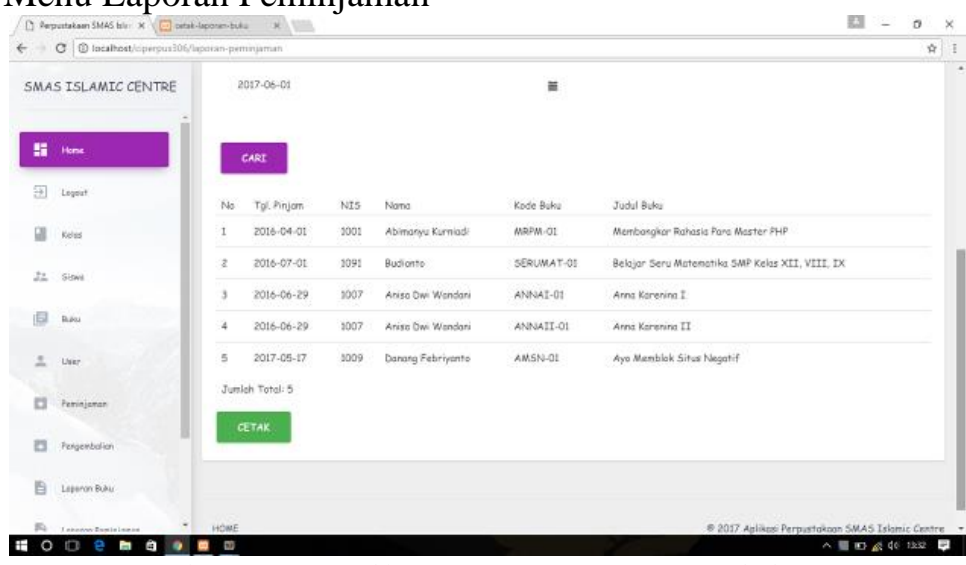

Gambar 9. Tampilan Menu Laporan Peminjaman

Pada gambar 3.5.9 di atas ini user bisa melihat dan mencetak laporan peminjaman buku.

\subsubsection{Tampilan Menu Laporan Pengembalian}

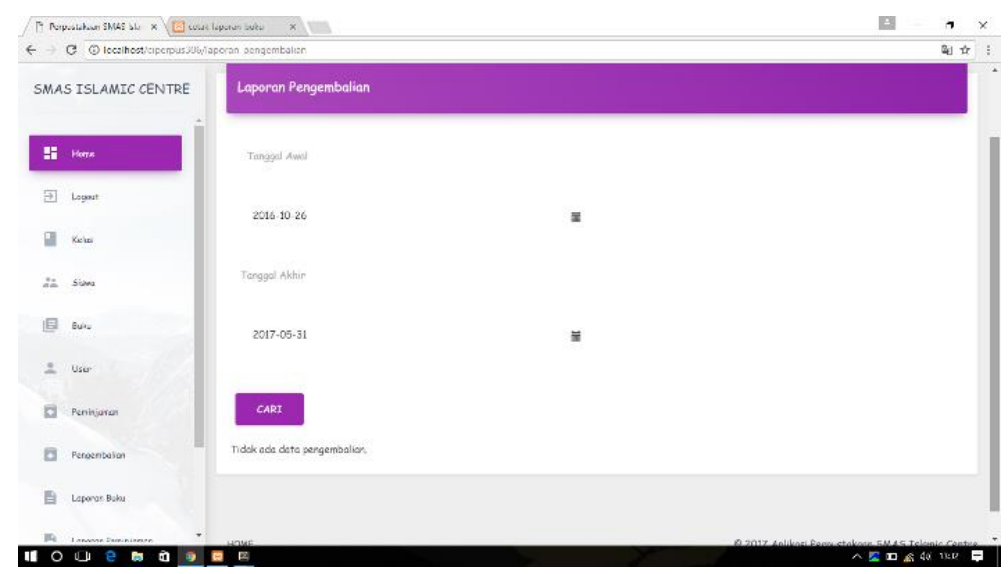

Gambar 10. Tampilan Menu Laporan Pengembalian

Pada gambar 3.5.10 di atas ini user dapat mencetak laporan pengembalian buku dengan mencari berdasarkan tanggal awal dan tanggal akhir. 


\subsubsection{Tampilan Menu Laporan Denda}

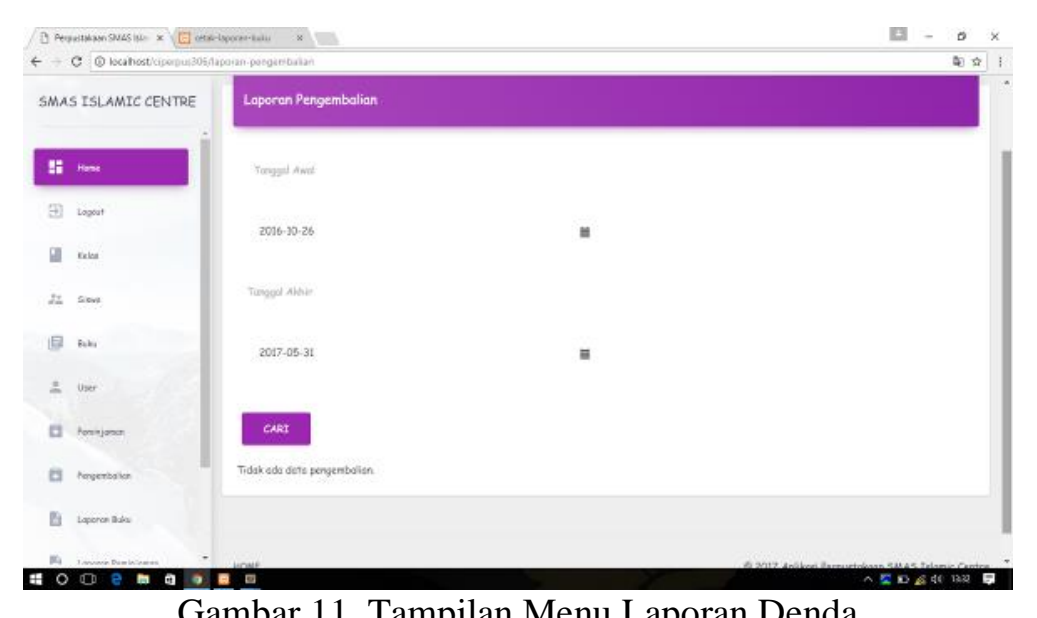

Gambar 11. Tampilan Menu Laporan Denda

Pada gambar 3.5.11 di atas ini user dapat mencetak laporan denda dengan mencari berdasarkan tanggal awal dan tanggal akhir.

\subsection{Respon User Terhadap Rancangan Sistem}

\begin{tabular}{|c|c|}
\hline Murid & Pengelola \\
\hline $\begin{array}{l}\text { 1. Proses registrasi member menjadi lebih } \\
\text { mudah } \\
\text { 2. Pencarian data buku menjadi lebih } \\
\text { mudah } \\
\text { 3. Buku yang tersedia lebih update sesuai } \\
\text { dengan minat baca murid } \\
\text { 4. Pengembalian buku menjadi lebih } \\
\text { sistematis }\end{array}$ & $\begin{array}{l}\text { 1. Penginputan data menjadi lebih mudah } \\
\text { 2. Pencarian data siswa yang meminjam } \\
\text { buku menjadi lebih mudah } \\
\text { 3. Pembuatan laporan yang otomatis } \\
\text { sesuai dengan inputan data. } \\
\text { 4. Lebih mudah mengetahui minat baca } \\
\text { siswa }\end{array}$ \\
\hline
\end{tabular}

3.7 Respon User Terhadap Sistem Sebelum dan Sesudah Diimplementasikan

Sebelum Sistem Diimplementasikan Sesudah Sistem Diimplementasikan

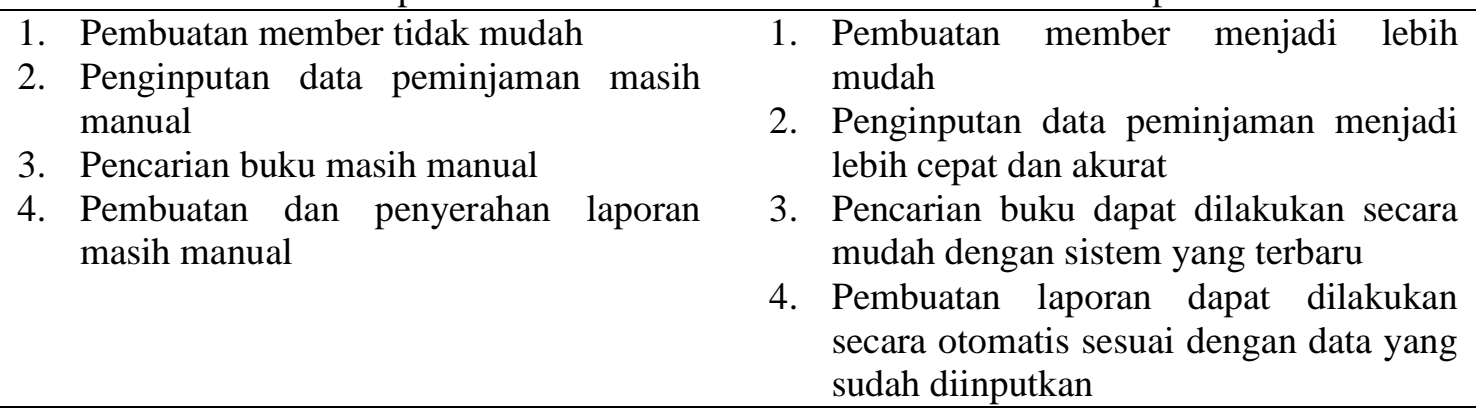

\section{KESIMPULAN}

Berdasarkan penelitian yang sudah peneliti kerjakan dengan ini maka dapat diambil sebuah kesimpulan berdasarkan permasalahan penelitian, yaitu pembuatan sistem pengolahan data perpustakaan yang komplek agar dapat memudahkan user dalam melakukan input data 
yang lebih cepat dan akurat, sistem pencarian data buku lebih mudah dikarenakan sistem pencarian buku otomatis yang telah di buat, dapat membantu kepala sekolah dalam pengecekan laporan data perpustakaan dengan mudah dengan memanfaatkan sistem terbaru yang telah di buat, pembuatan sistem monitoring minat baca siswa agar pihak sekolah dapat mengetahui seberapa besar minat baca siswa dan buku apa saja yang sering di pinjam siswa.

\section{SARAN}

Untuk memaksimalkan aplikasi berbasis web ini penulis menyarankan perlu adanya pelatihan untuk user yang akan menggunakan system aplikasi ini sebagai administrator agar dapat dimanfaatkan dengan baik kemudian perlu adanya pengembangan system aplikasi seperti ini yang uptodate yang dapat meningkatkan mutu system yang terakhir perlu adanya system yang kompleks dimana semua tugas dapat dikerjakan dalam satu system tersebut.

\section{DAFTAR PUSTAKA}

[1] Rio Novriliam, Yunaldi., 2012, Pemanfaatan Perpustakaan Sekolah Sebagai Pusat Sumber Belajar Di Sekolah Dasar Negeri 23 Painan Utara, Jurnal Ilmu Informasi Perpustakaan dan Kearsipan,No.1,Vol.1,141, http://ejournal.unp.ac.id/index.php/iipk/article/viewFile/499/420.

[2] Subhan, Mohamad., 2012, Analisan Perancangan Sistem. Jakarta : Lentera Ilmu Cendekia.

[3] Taufiq, Rohmat. 2013. Sistem Informasi Manajemen.Yogyakarta: Graha Ilmu.

[4] Hustinawati, Albert Kurnia Himawan dan Latifah. 2014, Performance Analysis Framework Codeigniter and CakePHP in Website Creation. International Journal of Computer Applications. Vol.94 No.20.

[5] Thwari, Amit S. dan Dr. S.E Yedey.2016.Study Of Codeigniter Technology. International Journal of Research in Computer \& Information Technology. Vol. 2 No.2.

[6] Lee, Sunguk. 2012. Unified Modeling Language (UML) for Database Systems and Computer Applications. International Journal of Database Theory and Application. Vol.5 No.1.

[7] Nugroho, Bunafit . Latihan Membuat Aplikasi Web PHP dan MySQL Dengan Dreamweaver MX $(6,7,2004)$ dan 8, Gava Media, Yogyakarta,2008.

[8] Hariadi, Fajar. 2013, PEMBUATAN SISTEM INFORMASI PERPUSTAKAAN PADA SDN SUKOHARJO PACITAN BERBASIS WEB. IJNS. Vol.2 No.4.

[9] Rizki, Juni Wati Sri. 2013, Optimalisasi Fungsi Perpustakaan Perguruan Tinggi Melalui Peran Pustakawan. Al-Kuttab. Vol.1 No.2.

[10] Nisak, Zuhrotun. 2013, Analisis SWOT Untuk Menentukan Strategi Kompetitif, http://journal.unisla.ac.id/pdf/12922013/4.pdf, diakses tgl 28 Mei 2017. 